\title{
Makna Simbolik dalam Konteks Komunikasi Antar Budaya (Kajian Fenomenologi Terhadap Seni Bela Diri Taekwondo)
}

\author{
Rachel Nelly, Sinta Paramita \\ rachel.915150117@stu.untar.ac.id,sintap@fikom.untar.ac.id \\ Fakultas Ilmu Komunikasi Universitas Tarumanagara
}

\begin{abstract}
South Korea has variety of cultures from language to arts. One of the best-known and most popular cultures from South Korea is Taekwondo. In Taekwondo there are various symbols that have meaning in them. The purpose of this research to know what is the meaning of the symbols in Taekwondo. This research used the theory of intercultural communication and the theory of symbolic meanings. The method used is Descriptive Qualitative Research Methodology. Qualitative data analysis technique used in this research is by observations and interviews. Based on the results of the interview the author obtained data about the procession carried out during the Taekwondo training, there were three processions from opening, intensive training, and closing. The symbols found in Taekwondo, is spoken words in the form of shouts, counts, calls, and the used of the Korean language, objects in the form of training uniform, belts, and protectors, gestures in the form of bowing, silence and technical movements, practice places, and promotion test events. Based on the interview results, can be concluded that the meaning contained in these symbols is self-formation which is influenced by moral values, social values, cultural values, and religious values for everyone directly involved in a cultural phenomenon in the form of Taekwondo.
\end{abstract}

Keywords: Martial Arts; Taekwondo; Symbolic Meaning, Intercultural Communication

\begin{abstract}
Abstrak
Korea Selatan memiliki beragam bentuk kebudayaan dari bahasa sampai dengan kesenian. Salah satu kebudayaan dari Korea Selatan yang terkenal dan diminati dunia adalah seni bela diri Taekwondo. Di dalam seni bela diri Taekwondo terdapat berbagai simbol yang memiliki makna didalamnya. Tujuan dari penelitian ini adalah untuk mengetahui makna yang terdapat pada simbol-simbol dalam seni bela diri Taekwondo khususnya di Indonesia. Penelitian ini menggunakan konsep komunikasi antar budaya dan teori makna simbolik. Penelitian ini menggunakan metodologi pendekatan penelitian kualitatif bersifat deskriptif, dengan penjaringan data fenomenologi. Teknik analisis data secara kualitataif yang digunakan di penelitian ini adalah dengan melakukan observasi dan wawancara. Berdasarkan hasil wawancara penulis mendapatkan data mengenai prosesi yang dilakukan pada saat akan latihan Taekwondo, terdapat tiga prosesi dari pembukaan, latihan intensif, dan penutup. Kemudian penulis juga mendapatkan simbol-simbol yang terdapat pada seni bela diri Taekwondo yaitu kata-kata terucap berupa teriakan, hitungan, panggilan, dan penggunaan bahasa Korea, objek berupa seragam latihan, sabuk, dan pelindung, gerak tubuh berupa gerakan membungkukkan badan, berdiam diri dan gerakan teknik, tempat latihan, dan peristiwa ujian kenaikan tingkat. Dapat disimpulkan terdapat makna yang terkandung dari simbol-simbol tersebut yakni pembentukan diri yang dipengaruhi oleh nilai moral, nilai sosial, nilai budaya, dan nilai agama bagi setiap orang yang terlibat langsung di dalam suatu fenomena budaya berupa seni bela diri Taekwondo
\end{abstract}

Kata Kunci: Seni Bela Diri; Taekwondo; Makna Simbolik; Komunikasi Antar Budaya 


\section{Pendahuluan}

Salah satu seni bela diri yang memiliki gerakan yang indah dan teratur terdapat dalam seni bela diri Taekwondo yang berasal dari Korea Selatan. Korea Selatan memiliki beberapa aliran seni bela diri lainnya seperti Ssireum dan Hapkido, tetapi Taekwondo merupakan seni bela diri dari Korea Selatan yang paling terkenal dan diminati baik di negara Korea sendiri maupun pada skala internasional. Hal ini membuat Taekwondo dinyatakan sebagai seni bela diri nasional Korea.

Masyarakat internasional semakin menaruh minat pada Taekwondo ketika fenomena Hallyu atau Korean Wave tersebar luas secara global di berbagai negara di dunia. Di Indonesia, seperti yang tertulis di media online Detik.com yang berjudul "“"Hallyu" dan Keberpihakan Kaum Muda" dimuat pada tanggal 22 Februari 2018 menginformasikan penyebaran Hallyu pada masyarakat Indonesia, khususnya bagi anak muda pada zaman ini. Di balik kesuksesan Korea Selatan dalam menyebarkan industri kreatif mereka ke seluruh penjuru dunia, ada keterlibatan beberapa pihak di pelbagai lini dan sektor. Pihak yang paling sentral dalam perkembangan Hallyu ini adalah pemerintah Korea Selatan melalui diplomasi kultural. Hal ini diperkuat dengan pidato resmi Presiden Kim Dae Jung dalam Third Conference of Tourism Promotion yang menyatakan bahwa strategi melalui kultural diperlukan untuk mengembangkan Korea Selatan melalui industri kreatif. Tidak hanya menyasar dunia perfilman dan musik, pemerintah Korea Selatan juga gencar memperkenalkan budaya melalui busana, kuliner dan seni bela diri. Anggaran pemerintah melalui Kementerian Budaya, Olahraga dan Turisme juga terus ditambah untuk memastikan hegemoni mereka di kancah internasional (Prasetyo, 2018).

Salah satu kontribusi pemerintah dan Kementerian Budaya, Olahraga dan Turisme Korea dalam penyebaran budaya mereka melalui seni bela diri Taekwondo adalah dengan menempatkan beberapa ahli-ahli Taekwondo dari Korea ke seluruh dunia selain itu Kukkiwon (pusat seni bela diri Taekwondo yang ada di Korea) sering memberikan kesempatan bagi setiap taekwondoin yang ada di negara-negara lain untuk mengikuti pelatihan langsung di Korea Selatan. Salah satu yang mendapat kesempatan ini adalah negara Indonesia. Sebanyak delapan atlet poomse dan sebelas atlet kyorugi Indonesia mengikuti pelatihan di Korea Selatan untuk menjalani pelatihan di sana sejak pekan ketiga Juni 2018. Berita ini dimuat di media online Antaranews pada 31 Mei 2018 dengan judul "Atlet Taekwondo Kembali Berlatih di Korea Selatan". Di dalam berita ini dituliskan bahwa ada sekitar sembilan belas orang atlet Taekwondo Indonesia yang menerima pelatihan di Korea Selatan untuk mempersiapkan diri dalam menghadapi kejuaraan di Vietnam, Korea, dan Asian Games nantinya (Santoso, 2018).

Menurut Suryadi (2003), seni bela diri Taekwondo adalah gabungan dari teknik bela diri, seni, olahraga, hiburan, dan filosofi. Taekwondo tidak hanya mengajarkan aspek fisik semata, seperti keahlian dalam bertarung, melainkan juga sangat menekankan filosofi dan unsur budaya Korea Selatan lainnya yang memiliki makna didalamnya. Taekwondo jika diartikan secara sederhana berarti seni yang menggunakan tangan dan kaki kosong. Tiga materi utama yang ada dalam Taekwondo adalah poomse (rangkaian jurus), kyukpa (teknik pemecahan benda keras), dan kyorugi (pertarungan).

Pada setiap gerakan dan atribut yang ada di dalam Taekwondo terkandung makna dan budaya Korea Selatan dari segi kesenian sampai dengan adat istiadat yang melatarbelakanginya. Selain gerakan dan atribut, banyak unsur budaya Korea lain 
yang terkandung didalamnya dan menjadi simbol-simbol yang memiliki makna. Oleh karena itu, penulis tertarik untuk meneliti lebih lanjut mengenai makna simbolik yang terkandung didalam seni bela diri Taekwondo. Sehingga penelitian ini bertujuan untuk mengetahui makna simbolik yang terkandung di dalam seni bela diri Taekwondo. Simbol-simbol apa saja yang terdapat di dalam seni bela diri Taekwondo dan makna yang terkandung didalam setiap simbol tersebut.

\section{Metode Penelitian}

Metode yang digunakan dalam penelitian ini adalah fenomenologi, dengan menggunakan pendekatan kualitatif. Menurut Rachmat Kriyantono (dalam Paramita, 2018) penelitian kualitatif adalah penelitian yang tidak menggunakan prosedur statistik. Bertujuan untuk menjelaskan fenomena dengan sedalam-dalamnya. Fenemenologi adalah studi tentang pengetahuan yang berasal dari kesadaran, atau cara memahami suatu objek atau peristiwa dengan mengalaminya secara sadar (Little John, 2003 dalam Hasbiansyah, 2008). Menurut Edgar dan Sedgwick (dalam Hasbiansyah, 2008) fenomenologi juga berupaya mengungkapkan tentang makna dari pengalaman seseorang. Makna tentang sesuatu yang dialami seseorang akan sangat tergantung bagaimana orang berhubungan dengan sesuatu itu.

Teknik pengumpulan data dalam penelitian ini dilakukan dengan melakukan wawancara mendalam dengan objek penelitian yaitu pelaku seni bela diri Taekwondo, dan budayawan Korea Selatan. Wawancara yang dilakukan penulis dilakukan satu kali dengan Ibu Carolina, Bapak Chandra, Bapak Aries, Bapak Reza, dan Bapak Rico selaku pelaku seni bela diri yang masih aktif melatih dan berlatih, serta Ibu Yanti selaku budayawan Korea Selatan. Wawancara dilakukan untuk mendapatkan informasi dari para narasumber mengenai makna simbolik yang terdapat di dalam seni bela diri Taekwondo dalam konteks komunikasi antar budaya.

Analisis data dilakukan dengan mentranskripsikan semua hasil wawancara dengan narasumber yang ada, kemudian setiap pernyataan yang relevan dikonstruksikan secara deskripsi menyeluruh mengenai makna dan esensi dari pengalaman para narasumber (Hasbiansyah, 2008). Kemudian yang menjadi objek dari penelitian ini adalah makna simbolik yang terkandung dalam seni bela diri Taekwondo dalam konteks komunikasi antar budaya, sedangkan subjek penelitiannya adalah beberapa pelaku dari seni bela diri Taekwondo.

\section{Hasil Penemuan dan Diskusi}

Berdasarkan hasil wawancara dengan narasumber yang ada, penulis menemukan filosofi yang mendasari Taekwondo adalah Taekwondo bukan hanya sebuah seni bela diri yang mengajarkan aspek fisik semata, seperti keahlian dalam bertarung, melainkan ajaran seni bela diri Taekwondo juga membawa budaya dan filosofi Korea didalamnya. Filosofi Taekwondo berakar pada semangat seni bela diri dan budaya bangsa Korea. Di dalam Taekwondo, setiap pelakunya juga harus berpegang pada lima elemen utama yaitu respect (respek pada diri sendiri maupun pada orang lain), humility (kerendahan hati), perseverance (ketekunan), self-control (pengendalian diri), dan honesty/kejujuran (wawancara dengan Chandra yang merupakan pelatih utama Beyond Fighter club pada 30 Oktober 2018 pukul 20:06 WIB di Jelambar Baru).

Selain itu penulis juga menemukan, prosesi latihan yang terdapat di dalam seni bela diri Taekwondo. Mengacu pada wawancara dengan Carolina pada 13 Oktober 
2018 pukul 11:36 WIB di Community Centre Taman Anggrek yang merupakan seorang Master Taekwondo, head Taekwondo instructor di club Nenggala. Berikut gambar dari tahapan proses yang terdapat di dalam seni bela diri Taekwondo:

Gambar 1. Prosesi dalam Seni Bela Diri Taekwondo

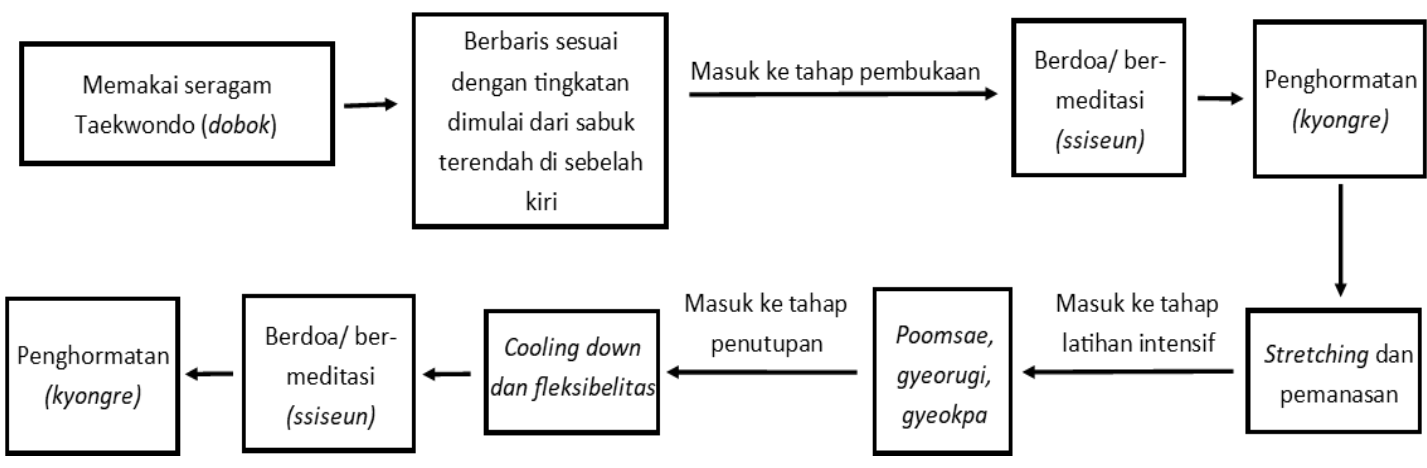

Sumber: Dokumentasi Peneliti (2018)

Berdasarkan wawancara dengan beberapa narsumber, penulis merangkum bahwa makna seni bela diri Taekwondo merupakan sebuah seni bela diri yang bukan hanya sekedar cara untuk bertarung tetapi juga merupakan sebuah seni yang indah, suatu budaya, pengembangan dan pembentukan diri seseorang, jalan hidup, dan juga suatu senjata yang kuat dan mematikan.

Mengacu pada teori Clifford Geertz yang menyatakan bahwa makna hanya dapat disimpan dalam simbol. Semua simbol, baik kata-kata yang terucapkan, sebuah objek seperti sebuah bendera, suatu gerak tubuh seperti melambaikan tangan, sebuah tempat seperti masjid atau gereja, atau suatu peristiwa seperti perkawinan, merupakan bagianbagian suatu sistem simbol. Simbol adalah objek atau peristiwa yang apa pun yang menunjuk pada sesuatu. Simbol itu meliputi apa pun yang dapat dirasakan atau dialami (dalam Sobur, 2017). Terdapat lima indikator simbol menurut Clifford Geertz berkaitan dengan penelitian penulis seputar Makna Simbolik Seni Bela Diri Taekwondo adalah sebagai berikut:

Tabel 1. Indikator Simbol Kata-Kata yang Terucap

\begin{tabular}{|c|c|}
\hline Indikator & Makna \\
\hline $\begin{array}{l}\text { Teriakan } \\
\text { (kihap) }\end{array}$ & $\begin{array}{l}\text { Menunjukan citra dari setiap taekwondoin yang kuat, bersemangat, dan } \\
\text { bertenaga dalam melakukan Taekwondo }\end{array}$ \\
\hline Hitungan & Menandakan kekompakan dan keserasian gerak sangat diperhatikan \\
\hline Panggilan & $\begin{array}{l}\text { Di dalam seni bela diri Taekwondo terdapat beberapa jenis panggilan } \\
\text { seperti sunbae, sabeom, sabeom-nim, master, dan grandmaster, } \\
\text { penggunaan panggilan ini memiliki makna bahwa setiap taekwondoin } \\
\text { harus menunjukan sikap menghargai dan menghormati kepada orang } \\
\text { yang memiliki tingkatan lebih tinggi baik berupa sabuk maupun jabatan } \\
\text { walaupun orang tersebut memiliki usia yang lebih muda. }\end{array}$ \\
\hline $\begin{array}{l}\text { Penggunaan } \\
\text { Bahasa Korea } \\
\text { pada teknik dan } \\
\quad \text { aba-aba }\end{array}$ & $\begin{array}{l}\text { Menandakan bahwa setiap taekwondoin yang berasal dari negara lain } \\
\text { atau yang bukan berasal dari negara Korea Selatan tetap menunjukan rasa } \\
\text { menghargai dan mengakui bahwa seni bela diri Taekwondo merupakan } \\
\text { bagian dari budaya Korea Selatan }\end{array}$ \\
\hline
\end{tabular}

Sumber: Dokumentasi Peneliti (2018) 
Dari tabel di atas, dapat disimpulkan bahwa makna dari kata-kata terucap di dalam seni bela diri Taekwondo adalah setiap orang yang mempelajari Taekwondo memiliki mental yang kuat, dapat bekerjasama dengan baik (nilai solidaritas), dan juga memiliki moral yang baik.

Tabel 2. Indikator Simbol Objek

\begin{tabular}{cl}
\hline Indikator & \multicolumn{1}{c}{ Makna } \\
\hline $\begin{array}{c}\text { Seragam } \\
\text { (dobok })\end{array}$ & Merupakan identitas Taekwondo \\
Sabuk (tti) & $\begin{array}{l}\text { Sebagai bentuk pencapaian diri seorang taekwondoin yang diukur } \\
\text { menggunakan sistem warna. Setiap tingkatan pada Taekwondo } \\
\text { mewakili satu warna yang sudah ditentukan. }\end{array}$ \\
& $\begin{array}{l}\text { Menandakan bahwa Taekwondo merupakan suatu seni bela diri yang } \\
\text { mengedepankan keselamatan dan keamanan dari setiap orang yang } \\
\text { mempelajarinya. }\end{array}$ \\
\hline
\end{tabular}

Sumber: Dokumentasi Peneliti (2018)

Setiap objek yang digunakan di dalam Taekwondo secara keseluruhan memiliki makna bahwa Taekwondo merupakan seni bela diri yang mengedepankan keamanan dan kenyamanan dari setiap orang yang mempelajarinya selain itu adanya nilai juang yang ditanamkan pada setiap taekwondoin agar dapat mengembangkan dan meningkatkan kemampuan dirinya lebih lagi.

Tabel 3. Indikator Simbol Gerak Tubuh

\begin{tabular}{|c|c|}
\hline Indikator & Makna \\
\hline $\begin{array}{l}\text { Gerakan berdiam } \\
\text { diri (ssiseun) }\end{array}$ & $\begin{array}{l}\text { Dilakukan dengan berdiam diri dengan posisi duduk bersila, tangan } \\
\text { berada di atas paha dan mata yang dipejamkan atau dapat dilakukan } \\
\text { dengan berdiri tegak, tangan dikepalkan pada sisi samping badan dan } \\
\text { mata dipejamkan kemudian dilanjutkan dengan berdoa atau } \\
\text { bermeditasi, hal ini dilakukan dengan maksud agar peserta latihan } \\
\text { dapat terhindar dari hal-hal yang tidak diinginkan seperti cendera. }\end{array}$ \\
\hline $\begin{array}{c}\text { Gerakan } \\
\text { membungkukan } \\
\text { badan (kyongre) }\end{array}$ & $\begin{array}{l}\text { Dilakukan dengan posisi badan membungkuk hingga berbentuk } 90 \\
\text { derajat. Gerakan ini ditujukan untuk semua orang baik kepada orang } \\
\text { memiliki tingkatan lebih tinggi, orang yang berusia lebih tua ataupun } \\
\text { juga kepada sesama. Maknanya adalah setiap taekwondoin memiliki } \\
\text { rasa hormat dan rasa menghargai kepada semua orang. }\end{array}$ \\
\hline Poomsae & $\begin{array}{l}\text { Sebagai pembuktian penguasaan teknik dan kemampuan fisik dari } \\
\text { seorang taekwondoin. }\end{array}$ \\
\hline Gyeorugi & $\begin{array}{l}\text { Seorang taekwondoin harus dapat mengaplikasikan teknik yang sudah } \\
\text { dipelajari dengan tepat selain itu harus adanya mental percaya diri, } \\
\text { sportif, dan tidak menggunakan teknik bertarung ini untuk hal-hal } \\
\text { negatif. GeSrakan ini menandakan setiap taekwondoin memiliki } \\
\text { mental keberanian sehingga mampu mengaplikasikan semua teknik } \\
\text { yang terdapat di dalam Taekwondo untuk membela diri secara nyata, } \\
\text { bukan hanya ke sasaran imajiner semata. }\end{array}$ \\
\hline
\end{tabular}


Merupakan pengaplikasian teknik Tekwondo dengan menghancurkan benda keras dengan tangan dan kaki kosong tanpa alat pelindung.

Gyeokpa Maknanya bukan hanya menunjukan kekuatan semata melainkan setiap taekwondoin harus dapat percaya pada dirinya sendiri baik dari segi kemampuan maupun pengaplikasian tekniknya sehingga gyeokpa dapat dilakukan dengan sempurna.

Sumber: Dokumentasi Peneliti (2018)

Makna dari gerak tubuh yang dilakukan di seni bela diri Taekwondo adalah seni bela diri Taekwondo menjalankan nilai religi, menjujung tinggi nilai moral dan sportifitas, mengasah mental keberanian dan kepercayaan diri serta kekuatan dan ketahanan fisik dari setiap orang yang mempelajari Taekwondo.

Tabel 4. Indikator Simbol Tempat

\begin{tabular}{cl}
\hline Indikator & \multicolumn{1}{c}{ Makna } \\
\hline $\begin{array}{c}\text { Tempat Latihan } \\
\text { (dojang) }\end{array}$ & $\begin{array}{l}\text { Tempat untuk berlatih dan mengembangkan diri. Makna dojang } \\
\text { sebenarnya melekat pada diri setiap orang yang sedang berlatih. }\end{array}$
\end{tabular}

\section{Sumber: Dokumentasi Peneliti (2018)}

Tempat yang digunakan untuk berlatih Taekwondo disebut sebagai dojang. Berdasarkan wawancara dengan Carolina, lokasi dojang dapat berada dimana saja, ketika orang -orang berkumpul untuk berlatih Taekwondo maka tempat tersebut dapat disebut sebagai dojang.

Tabel 5. Indikator Simbol Peristiwa

\begin{tabular}{cc}
\hline Indikator & Makna \\
\hline $\begin{array}{c}\text { Ujian Kenaikan } \\
\text { Tingkat }\end{array}$ & Sebagai bentuk pembuktian diri dari seorang taekwondoin. \\
\hline
\end{tabular}

Sumber: Dokumentasi Peneliti (2018)

Peristiwa yang terjadi secara rutin di dalam Taekwondo adalah ujian kenaikan tingkat. Lulus ujian kenaikan tingkat menjadi salah satu syarat agar seorang taekwondoin dapat lanjut ke tingkat selanjutnya. Aries mengatakan bahwa seorang taekwondoin dapat lanjut ke tingkat selanjutnya jika ia sudah dianggap pantas baik dari segi teknik, mental, dan perilakunya. Ujian kenaikan tingkat ini bermakna sebagai pembuktian diri dari seorang taekwondoin. Karena seharusnya kemampuan, mental, dan perilaku dari taekwondoin tersebut sesuai dengan tingkatan sabuk yang ia miliki.

Mengacu pada indikator simbol milik Geertz, dapat disimpulkan bahwa makna simbolik yang terkandung di dalam seni bela diri Taekwondo adalah sebagai bentuk pengembangan, pembentukan, dan pembuktian diri dari segi mental keberanian dan kepercayaan diri, moral dan sportifitas, fisik, dan penerapan nilai budaya pada setiap orang yang mempelajarinya baik saat melakukan Taekwondo maupun didalam kehidupan kesehariannya.

Komunikasi Antar Budaya menurut Samovar, Porter \& McDaniel (2010, dalam Paramita dan Sari, 2016) menjelaskan bahwa komunikasi lintas budaya atau antarbudaya terjadi ketika anggota dari satu budaya tertentu memberikan pesan kepada 
anggota dari budaya yang lain. Lebih tepatnya, komunikasi antarbudaya melibatkan interaksi antara orang-orang yang persepsi budaya dan sistem simbolnya cukup berbeda dalam suatu komunikasi. Singkatnya komunikasi antar budaya komunikasi yang terjadi antar orang atau kelompok dari budaya yang berbeda. Seni bela diri Taekwondo yang merupakan bagian dari budaya Korea Selatan sudah tersebar hampir di seluruh dunia, salah satunya di Indonesia. Ketika seni bela diri Taekwondo yang masuk ke Indonesia, akan terjadi proses negosiasi makna karena faktor latar belakang kebudayaan yang berbeda.

Chen dan Starosta (dalam Liliweri, 2003) mengatakan bahwa komunikasi antar budaya dilakukan dengan negosiasi untuk melibatkan manusia di dalam pertemuan antar budaya yang membahas satu tema atau penyampaian tema melalui simbol yang sedang dipertentangkan. Ketika proses negosiasi telah dilakukan maka akan terjadi pergeseran makna. Berdasarkan hasil wawancara dengan beberapa informan, penulis menemukan beberapa makna simbolik yang terdapat di dalam seni bela diri Taekwondo yang bergeser ketika masuk ke Indonesia, yaitu sebagai berikut:

Tabel 6. Pergeseran Makna Simbolik pada Taekwondo di Indonesia

\begin{tabular}{|c|c|c|}
\hline Indikator & Makna Asli & Makna yang berubah \\
\hline Panggilan & $\begin{array}{l}\text { Untuk menunjukan rasa } \\
\text { menghargai dan menghormati } \\
\text { kepada orang yang memiliki } \\
\text { tingkat lebih tinggi }\end{array}$ & $\begin{array}{l}\text { Setiap orang yang mempelajari } \\
\text { Taekwondo adalah seorang yang } \\
\text { "gila hormat". Karena sering } \\
\text { disalahgunakan } \\
\text { taekwondoin Indonesia }\end{array}$ \\
\hline $\begin{array}{l}\text { Gerakan berdiam } \\
\text { diri (ssiseun) }\end{array}$ & $\begin{array}{l}\text { Dilakukan dengan bermeditasi, } \\
\text { agar dapat berkonsentrasi sehingga } \\
\text { maknanya dapat terhindar dari } \\
\text { kesalahan yang dapat berujung } \\
\text { menjadi cendera saat berlatih. }\end{array}$ & $\begin{array}{ll}\text { Menunjukan bahwa setiap } \\
\text { taekwondoin } & \text { Indonesia } \\
\text { menjunjung tinggi } & \text { nilai-nilai } \\
\text { agama. Ssiseun } & \text { dilakukan } \\
\text { dengan berdoa. } & \end{array}$ \\
\hline $\begin{array}{c}\text { Gerakan } \\
\text { membungkukan } \\
\text { badan (kyongre) }\end{array}$ & $\begin{array}{l}\text { Menunjukan rasa segan dan } \\
\text { menandakan mereka sangat } \\
\text { menghormati orang tersebut. } \\
\text { Dilakukan dengan membungkukan } \\
\text { badan } 90 \text { derajat. }\end{array}$ & $\begin{array}{l}\text { Menunjukan rasa hormat yang } \\
\text { dipaksakan. Karena gerakan ini } \\
\text { sering dilakukan } \\
\text { taekwondoin Indonesia dengan } \\
\text { sembarang dan tidak sesuai } \\
\text { ketentuan }\end{array}$ \\
\hline
\end{tabular}

Sumber: Dokumentasi Penulis

\section{Simpulan}

Makna simbolik yang terkandung di dalam seni bela diri Taekwondo adalah sebagai bentuk pengembangan, pembentukan, dan pembuktian diri dari segi mental keberanian dan kepercayaan diri, moral dan sportifitas, fisik, penerapan nilai budaya pada setiap orang yang mempelajarinya baik saat melakukan Taekwondo maupun didalam kehidupan kesehariannya.

Memiliki latar belakang budaya yang berbeda antara Indonesia dan Korea Selatan membuat terjadinya proses negoasiasi makna yang akhirnya menyebabkan pergeseran makna pada seni bela diri Taekwondo di indonesia.

Selanjutnya, penulis memberikan saran bahwa pengenalan Taekwondo baik dari segi penggunaan bahasa dan aspek budaya lainnya dapat diperdalam lagi khususnya untuk orang-orang yang bukan merupakan orang Korea, karena sering terjadinya salah 
pengucapan dan pemaknaan yang salah oleh orang asing. Kemudian, untuk para pelaku di industri iklan, diharapkan nilai-nilai dalam Taekwondo dapat diserap dan diterapkan sehingga dapat menjadi pegangan dan pedoman untuk mengembangkan, membentuk, dan membuktikan diri di dalam industri kreatif tersebut.

\section{Ucapan Terima Kasih}

Ucapan terima kasih diberikan kepada Fakultas Ilmu Komunikasi Tarumanagara dan juga para narasumber yaitu: Carolina, Chandra, Yanti, Aries, Reza, dan Rico yang telah membantu sebagai narasumber dan semua pihak yang telah mendukung dan membantu dalam penelitian ini.

\section{Daftar Pustaka}

Hasbiansyah, O. (2008). Pendekatan Fenomenologi: Pengantar Praktik Penelitian dalam Ilmu Sosial dan Komunikasi. MediaTor (Jurnal Komunikasi), 9(1), 163180

Kim, Sang H., Kuk Hyun Chung, \& Kyung Myong Lee. (1999). Taekwondo Kyorugi: Olympic Style Sparring (Edisi ke 2). Wethersfield: Turtle Press

Liliweri, A. (2003). Makna Budaya dalam Komunikasi Antarbudaya. Yogyakarta: LKiS Pelangi Aksara

Paramita, S. (2018). Pergeseran Makna Budaya Ondel-Ondel Pada Masyarakat Betawi Modern. Jurnal Bakti Masyarakat Indonesia, 1(1), 133-138

Paramita, S., \& Wulan Purnama S. (2016). Komunikasi Lintas Budaya dalam Menjaga Kerukunan antara Umat Beragama di Kampung Jaton Minahasa. Jurnal Pekommas, 1(2), 153 - 166

Park, Yeon Hee, Yeon Hwan Park, \& Jon Gerrard. (2013). The Ultimate Reference Guide to The World's Most Popular Black Belt Martial Art Tae Kwon Do. edisi ke-3. New York: Skyhorse Publishing Pers

Prasetyo, Indra Dwi. (Februari 2018). "Hallyu" dan Keberpihakan Kaum Muda. <https://news.detik.com/kolom/3880620/hallyu-dan-keberpihakan-kaummuda>, diakses tanggal 27 Agustus 2018 pukul 15.40 WIB

Santoso, Imam. (Mei 2018). Atlet Tae Kwon-Do Kembali Berlatih di Korea Selatan. $<$ https://www.antaranews.com/berita/715043/atlet-tae-kwon-do-kembaliberlatih-di-korea-selatan>, diakses tanggal 27 Agustus 2018 pukul 16.12 WIB

Sobur, Alex. (2017). Semiotika Komunikasi. edisi ke-5. Bandung: Remaja Rosdakarya Suryadi, V. Yoyok. (2003). Taekwondo Poomse Taeguk. Jakarta: PT. Gramedia Pustaka Utama. 